\title{
Morpheme-specific Exceptional Processes and Emergent Unmarkedness in Vowel Harmony
}

\author{
Shakuntala Mahanta
}

In this paper I discuss exceptional occurrences in the nominal and verbal morphology of Assamese and the role of indexed markedness constraints in accounting for these exceptions. Assamese vowel harmony is a 'directional' right-to-left regressive harmony system, which normally ignores morphological boundaries. In contrast to the general process of harmony, this work shows that some morphemes can influence vowel harmony and result in exceptional patterns. Following Pater (2006) it is shown that indexation of markedness constraints can account for these exceptional occurrences. This work also shows that the caveat in Pater (2006) about such constraints' ability to subvert the universal constraint ranking ROOT FAITH >> AFFIX FAITH is indeed borne true. Consequently, the Assamese examples show that indexed constraints lead to an exceptional alternation where [ \pm Back] harmony occurs only in the root and the suffixal [ \pm Back] values remain unaltered. I argue that this reversal is a result of confluence of several factors leading to the theoretically motivated observation that some unexpected processes in OT may be emergent. The paper also deals with another exceptional pattern where the combined outcome of vowel harmony and a morphological requirement of avoiding vowel-vowel sequences results in an exceptional pattern of syllabification. Contextualising these occurrences to the need for indexed markedness constraints, it is shown that the indexation of *HIATUS is able to analyse these occurrences. Furthermore, it is shown that hiatus avoidance can be the result of varying markedness requirements and it need not be the result of a single motivation of unmarkedness dictated by the overarching grammatical structure. *HIATUS is satisfied by both epenthesis as well as vowel deletion, and in one instance a morpheme even prefers a hiatal situation over non-hiatus. The exceptional occurrences show that markedness requirements and reversals may be often emergent, and therefore a result of a particular relation that a specific morpheme construes to be the least marked. 


\section{Introduction}

In the first part of the paper I will present data and analysis of exceptional triggering of harmony by the two morphemes /-iya/ and /-uwa/ in Assamese. This process of triggering exceptional realisation of harmony can be characterised as morphologically induced harmony, which is obtained at the cost of flouting the highly ranked phonological constraint IDENT [Low] (which prevents any alteration of the low vowel /a/). In the first case, a morpheme triggers exceptional alteration on the otherwise non-participating vowel /a/. The application of harmony in this context violates the constraint IDENT [Low], which is otherwise highly ranked in the phonology of Assamese. In the second case, the presence of /-iya/ and /-uwa/ leads to the emergence of front harmony whenever there are preceding front vowels under the same conditions as described in the first case. In the rest of the paper I describe these morpho-phonological interactions and discuss some aspects of exceptional morpho-phonemic interactions, which have consequences for a theory aiming to handle exceptions in general, and Optimality Theory (Prince and Somlensky 1993/2004) in particular.

Section 1 presents a general background to Assamese vowel harmony and provides an overview of the conditions which leads to exceptionality. Section 2 deals with data and problems relating to the exceptional triggering of harmony by the affixes /-iya/ and /-uwa/ in Assamese. Section 3 presents an elaborate analysis of the exceptional problems discussed in section 2. This section lays down the theoretical precept of locality in exceptionality, and deals with the problems keeping locality as the guiding criterion in a theory of constraint indexation. This section also shows how emergent front harmony can be handled within a theory of lexical indexation. Section 4 briefly discusses alternative theoretical approaches and the paper ends with a conclusion in section 4 .

\subsection{Introduction to Assamese vowel harmony}

Assamese has an eight vowel inventory consisting of /i, u, $u, e, o, \varepsilon, o, a /$. Assamese harmony is regressive and always triggered by an immediately following $/ \mathrm{i} / \mathrm{or} / \mathrm{u} /$. The harmony constraint produces the alternations $/ \varepsilon / \rightarrow[\mathrm{e}], / \mathrm{J} / \rightarrow$ [o], and $/ \mathrm{v} / \rightarrow / \mathrm{u} /$, where the vowel $/ \mathrm{a} /$ is opaque to vowel harmony. However, /a/ exceptionally undergoes harmony under the influence of the morphemes /iya/ and / -uwa/. Assamese vowel harmony is typically word-based, excluding compounded words and larger morpho syntactic domains. Vowel harmony in Assamese is therefore a right-to-left process and there are no morphologically significant positions which either trigger or target it. The Assamese vowel harmony examples are given below: 
(1) Vowel harmony triggered by the /i/ suffix Root $^{1}$ Gloss Suffix Derivation Gloss
a. tel
teli
'oily'
b. upor 'above' i
upori 'in addition'
c. $\mathrm{k}^{\mathrm{h}}$ oros 'spend' $\mathrm{i}$
$\mathrm{k}^{\mathrm{h}}$ orosi 'spendthrift'

In this section I present a basic OT analysis of Assamese vowel harmony and I define the relevant constraints below:

(2) $\quad *[-$ ATR $][+$ ATR $]$

Assign a violation mark to a candidate containing a [-ATR] segment followed by a $[+$ ATR $]$ segment.

(3) IDENT [ATR]

A candidate containing a segment in the output and its correspondent in the input must have identical specifications for [ATR].

\section{(4) IDENT[High]}

A candidate containing a segment in the output and its correspondent in the input must have identical specifications for [High].

(5) $\quad *[+$ High,, -ATR,, Back $]$

Assign a violation mark to a candidate containing vowels with the feature values $[-$ ATR $][+$ High $]$ and $[-$ Back $]$

(6) Vowel harmony in Assamese

\begin{tabular}{|l||l:l|l|l|}
\hline$/$ kor/+/i/‘do' & $\begin{array}{l}\text { IDENT } \\
{[ \pm \text { INF }}\end{array}$ & {$[-$ ATR, } & $*[-$ ATR $]$ & IDENT \\
{$\left[\begin{array}{l}{[\text { High, }- \text { Back }]} \\
{[+ \text { ATR }]}\end{array}\right.$} & {$[ \pm$ ATR $]$} \\
\hline \hline a. kori & & & $* !$ & \\
\hline b. ${ }^{*}$ kori & & & & $*$ \\
\hline c. kuri & $* !$ & & & $*$ \\
\hline d. kuri & & $* !$ & & $*$ \\
\hline
\end{tabular}

The tableau above shows that the constraints IDENT [High] and * $[-$ ATR, + High, - Back] are undominated in Assamese ${ }^{2}$. The high ranking IDENT [HIGH] Constraint does not allow height values to alter. The harmony driving constraint $*[-\mathrm{ATR}][+\mathrm{ATR}]$ is ranked above IDENT [ATR], leading to the alteration of [ATR] values only. The constraint * $[-$ ATR $][+$ ATR $]$ plays a crucial role in prohibiting output sequences with an [ATR] mismatch in their feature specifications. 


\subsection{Blocking by $/ \mathrm{a} /$ and $/ \mathrm{a} /-$ raising}

Whereas /a/ alternates with [e], /a/ alternates with [o] and $/ \mho /$ alternates with $/ u /$, /a/ is a non-alternating vowel in the inventory. Therefore, /a/ behaves as a phonologically opaque vowel. It is protected by the faithfulness constraint IDENT [Low] as /a/'s involvement in harmony would also result in the violation of * [+ATR +Low], an undominated constraint, because low [+ATR] vowels are absent from the surface inventory ${ }^{3}$.

Assamese trisyllables with medial /a/ and final /i/

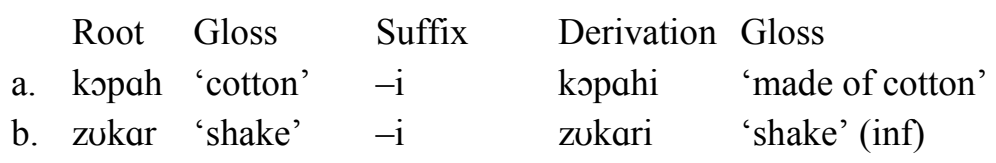

The examples in (7) represent words in which /a/ occurs word-medially and there is no agreement with the [+ATR] value of the triggering suffixal vowel. Instead, the leftmost vowel is [-ATR] and has not been influenced by the [+ATR] vowel in the right periphery. There are also various suffixes with $/ \mathrm{a} /$, which result in opacity and the ones shown below are some such examples:

(8) /-aru/ and /-ali/ block harmony

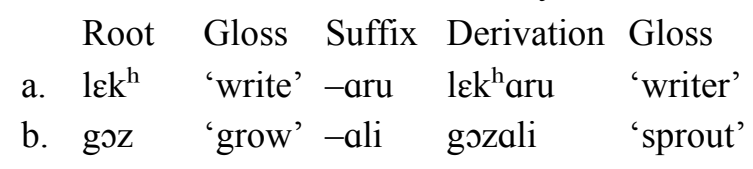

The tableau below shows how IDENT [Low] is responsible for blocking harmony.

(9) /a/ remains unaltered in the presence of a following trigger

\begin{tabular}{|c|c|c|c|c|c|}
\hline $\begin{array}{l}\text { I: } \\
\text { /kəpah/+/i// }\end{array}$ & $\begin{array}{l}*[+ \text { ATR } \\
+ \text { Low }]\end{array}$ & $\begin{array}{l}\text { IDENT } \\
{[\text { Low }]}\end{array}$ & $\begin{array}{l}*[-\mathrm{ATR}] \\
{[+\mathrm{ATR}]}\end{array}$ & $*[-\mathrm{High}+\mathrm{ATR}]$ & $\begin{array}{l}\text { IDENT } \\
\text { [ATR] }\end{array}$ \\
\hline a. kopahi & & & * & & \\
\hline b. kopohi & & ! & & $*$ & * \\
\hline c. kopæhi & $* !$ & & & $*$ & * \\
\hline
\end{tabular}

The inertness of /a/ to the harmony process is accounted for by high ranked IDENT [Low] and *[+ATR + Low]. These constraints are ranked higher than the harmony driving constraint * $[-\mathrm{ATR}][+\mathrm{ATR}]$, and therefore the candidate in (9)-a which does not undergo any /a/ alteration is the winning candidate. 


\section{3. /a/-raising: Local exceptional triggering}

In this section, I will first show in detail the environments in which the exceptional morpho-phonological patterns alluded to above, occur. Before going into the details of exceptionality, I will draw examples from the regular morphology to show the operations of vowel harmony in a regular derived environment domain. In the examples in (10) and (11) below, the [High] vowels in the suffixes trigger [+ATR] harmony in the preceding root/stem.

(10) Monosyllabic roots and regular vowel harmony

$\begin{array}{llllll} & \text { Root } & \text { Goss } & \text { Suffix } & \text { Derived } & \text { Gloss } \\ \text { a. } & \text { mer } & \text { 'wind' } & - \text { uwa } & \text { meruwa } & \text { 'wind' (causative) } \\ \text { b. } & \mathrm{d}^{\text {h }} \mathrm{vl} & \text { 'drum' } & - \text { iya } & \text { d } \text { huliya } & \text { 'drummer' } \\ \text { c. } & \text { tel } & \text { 'oil' } & \text {-iya } & \text { teliya } & \text { 'oily' }\end{array}$

(11) Regular vowel harmony in bisyllabic stems
Root Gloss
Suffix Derived Gloss
a. boyox 'age' -iya boyoxiya 'aged'
b. bosor 'one year' $-\mathrm{i}$ bosori 'yearly'
c. gubor 'dung' -uwa guboruwa 'fly' (with dung-like smell)

The examples above show that there is ample evidence that the adjectival suffixes / -iya/ and /-uwa/ trigger regular [ATR] harmony in the preceding [-ATR] vowels $/ \varepsilon / / 0 /$ and $/ \mho /$.

\section{2. /a/-raising: Local exceptional triggering}

/a/-raising occurs when the two affixes /-iya/ and /-uwa/ trigger harmony in morphemes containing /a/. In monosyllabic stems, /a/ always adapts itself to /o/, when followed by /-iya/ or /-uwa/.

(12) /a/-raising in monosyllabic roots

$\begin{array}{llllll} & \text { Root } & \text { Gloss } & \text { Suffix } & \text { Derivation } & \text { Gloss } \\ \text { a. } & \text { sal } & \text { 'roof' } & - \text { iya } & \text { soliya } & \text { 'roof-ed' } \\ \text { b. } & \text { dal } & \text { 'branch' } & - \text { iya } & \text { doliya } & \text { 'branch-ed' } \\ \text { c. } & \text { d }^{\text {har }} & \text { 'debt' } & - \text { uwa } & \text { d } \text { horuwa } & \text { 'debtor' }\end{array}$


d. mar 'beat'(v) -uwa moruwa 'beat'(causative)

The data below show that / $\mathrm{a} /$-raising is restricted to the vowel adjacent to the triggering morpheme. /a/-raising does not occur when /a/ is not adjacent to the triggering vowel:

(13) $/ \mathrm{a} /$ does not change when it is not adjacent to the triggering vowel ${ }^{4}$

$\begin{array}{llllll} & \text { Root } & \text { Gloss } & \text { Suffix } & \text { Derivation } & \text { Gloss } \\ \text { a. } & \text { patol } & \text { 'light' } & \text {-iya } & \text { patoliya } & \text { 'lightly' } \\ \text { b. } & \text { apod } & \text { 'danger' } & - \text { iya } & \text { apodiya } & \text { 'in danger' } \\ \text { c. } & \text { alax } & \text { 'luxury' } & - \text { uwa } & \text { aloxuwa } & \text { 'pampered' } \\ \text { d. } & \text { ad }^{\text {h }} \text { a } & \text { 'half' } & - \text { uwa } & \text { ad }^{\text {horuwa }} & \text { 'halved' }\end{array}$

The examples (13) a - b have the segmental composition /CaCo../ and harmony triggered by /-iya/ only affects the immediately preceding [-ATR] vowel /o/, but the non-adjacent /a/ does not undergo harmony. However, this is not different from the behaviour of similar sequences when harmony is triggered by suffixes other than /-iya/ and /-uwa/ (see examples in (18) and (19)), as they would all produce the same result. The local triggering behaviour of /-iya/ and /-uw / is exemplified very clearly by the examples in (13) d-e. In these cases, there are two instances of $/ \mathrm{a} /$, but only the vowel adjacent to the triggering vowel undergoes harmony. /a/-raising triggered by /-iya/ and /-uwa/ ${ }^{5}$ violates IDENT [Low], but IDENT [Low] violations are as minimal as possible, because /a/raising is restricted to the smallest possible domain.

The participation of only two morphemes /-iya/ and /-uwa/ in triggering exceptional realisation of harmony can be characterised as morphologically induced harmony, which is obtained at the cost of flouting the highly ranked phonological constraint IDENT [Low] (which prevents any alteration of the [Low] vowel $/ \mathrm{a} /$ ). This violation leads to the harmonising behaviour of the normally opaque vowel $/ \mathrm{a} /$ in such a way that it alters to a vowel which is already present in the surface phonetic inventory. Exceptional triggering of the type discussed in this paper cannot be deemed to be the same as dominance in vowel harmony or other kinds of exceptionalities recorded in the literature. In Assamese, there are no instances of exceptional root or suffixal morphemes which undergo harmony under special circumstances or cases where morphemes do not undergo harmony because they are opaque to the spreading process. The Assamese data are unique cases of exceptional triggers. However, they are only unique as far as 
exceptionality in vowel harmony is concerned. Such cases of local exceptionality are found in other morpheme specific phonology as well (see Pater 2006, for an example of Finnish).

\subsection{Further domain related issues in exceptional [+ATR] harmony}

The examples below show that /a/-raising does not occur when the stem is longer than two syllables (the final / $/$ / in trisyllablic roots deletes itself).

(14) No /a/-raising in trisyllables with final /a/

\begin{tabular}{|c|c|c|c|c|}
\hline Word & Gloss & Suffix & Derivation & $\begin{array}{l}\text { Gloss } \\
\text { 'peevish or irritable' }\end{array}$ \\
\hline sokola & 'a round flat piece' & -iya & sokoliya & 'slice' \\
\hline pohora & $\begin{array}{l}\text { 'guarding' } \\
\text { (VERBAL NOUN) }\end{array}$ & -iya & pohoriya & 'guard' \\
\hline
\end{tabular}

These examples have been presented to show that there is a minimal domain in which / /-raising can occur and it is limited to the first two syllables of a word. In all likelihood, there is a constraint which limits /a/-raising to the foot which bears primary prominence in Assamese (Assamese follows a strong-weak or trochaic rhythm, Goswami 1982).

\subsection{1. /a/-raising and prefixes}

The examples below show how the prefixal vowels / $\varepsilon-/$ and /o-/ change their feature value for $[ \pm \mathrm{ATR}]$ in an environment where there is a $/ \mathrm{i} /$ or $/ \mathrm{u} /$ on the right side of the morphological word:

(15) Prefixal participation in [+ATR] harmony

\begin{tabular}{|c|c|c|c|c|c|}
\hline $\begin{array}{l}\text { Prefix } \\
0-\end{array}$ & $\begin{array}{l}\text { Root } \\
g^{\text {hor }}\end{array}$ & $\begin{array}{l}\text { Gloss } \\
\text { 'home' }\end{array}$ & $\begin{array}{l}\text { Suffix } \\
-\mathrm{i}\end{array}$ & $\begin{array}{l}\text { Derivation } \\
\operatorname{og}^{\mathrm{h}} \text { ori }\end{array}$ & $\begin{array}{l}\text { Gloss } \\
\text { 'homeless' }\end{array}$ \\
\hline & $\mathrm{k}^{\mathrm{h}} \mathrm{UZ}$ & 'steps' & -iya & $\mathrm{ek}^{\mathrm{h}} \mathrm{uziya}$ & 'going slowly \\
\hline
\end{tabular}

Similarly, a process of /a/-raising similar to the one observed in examples (18) and (19) applies when /a/ belongs to the root and $/ \varepsilon-/$ or $/ \mathrm{o}-/$ are prefix vowels.

(16) /a/-raising and prefixes

Prefix Gloss Root Gloss Suffix Derivation Gloss

a. $\varepsilon^{-}$one sal roof -iya esoliya one roof-ed 

b. $\varepsilon-$
one
dal
branch -iya
edoliya one branch-ed
c. $\varepsilon-$
leaf -iya
epotiya one branch-ed
d. $\varepsilon-$
pat
slope -iya
ed ${ }^{\text {h }}$ oliya sloping to a side
e. so-
month -iya
somohiya six months old

In the examples in (16), the root /a/ does not change its value for the feature $[ \pm$ Back $]$ to that of the preceding prefixal vowel. The reason for this behaviour is dependent on the affiliation of $/ \varepsilon-/$ and $/ \mathrm{o}-/$ as prefixal vowels. Under such circumstances, the $[ \pm \mathrm{Back}]$ value that the vowel $/ \mathrm{a} /$ alternates with depends on the intrinsic [+Back] value of $/ \mathrm{a} /$, so that it invariably changes to [o] instead of [e]. Given this description of the pattern of alternation, I will now discuss the locality requirements in these exceptional environments.

2.2. a/-raising in the presence of preceding mid vowels - dual exceptionality

In the examples presented till now, we have seen that local/a/-raising shows up in words of the following configuration:

Schema of /a/-raising
a. (C) iCa+iya
b. (C)aCa+iya

In words with the vowel sequences above, the locality of the process always result in words where only the / $\mathrm{a} /$ adjacent to the triggering vowel undergoes raising, resulting in words of the type (C)VCoCiya.

This is only a partial analysis of the exceptional occurrences in Assamese vowel harmony. I have not yet presented the data where the consequence of the exceptional morphemes /iya/ and /uwa/ are seen in the presence of mid vowels preceding the low vowel, i.e. sequences like $/ \mathrm{CaCa}+\mathrm{iya} /$. Assamese vowel harmony is iterative and regressive, hence if $/ \mathrm{a} /$ undergoes harmony and produces a [+ATR] output, it is plausible that the resultant [+ATR] vowel will also trigger

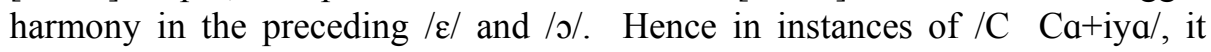
could be predicted that the outcome of /a/-raising would result in /CeCoCiya/, because /CeCoCiya/ will violate the constraint driving iterative vowel harmony, i.e. ${ }^{*}[-\mathrm{ATR}][+\mathrm{ATR}]$. A quick look at the data below shows that this prediction is true, but the hypothesis falls short of predicting another exceptionality in the actually observed data. In disyllabic stems, apart from [+ATR] harmony, the $[ \pm$ Back] feature that $/ \mathrm{a} /$ assumes for raising is determined by the root-initial vowel $^{6}$. 
/a/-raising triggered by /-iya/

$\begin{array}{llllll} & \text { Word } & \text { Gloss } & \text { Suffix } & \text { Derivation } & \text { Gloss } \\ \text { a. } & \text { kopal } & \text { 'destiny' } & - \text { iya } & \text { kopoliya } & \text { 'destined' } \\ \text { b. } & \text { d }^{\text {h}} \text { cmali } & \text { 'play' } & - \text { iya } & \mathrm{d}^{\text {hemeliya }} & \text { 'playful' } \\ \text { c. } & \text { gulap } & \text { 'rose' } & - \text { iya } & \text { gulopiya } & \text { 'pink' } \\ \text { d. } & \text { misa } & \text { 'lie' } & \text {-iya } & \text { misoliya } & \text { 'liar' }\end{array}$

\begin{tabular}{llllll}
\multicolumn{5}{l}{ /a/-raising triggered by /-uwa/ } \\
Word & Gloss & Suffix & Derivation & Gloss \\
a. & clah & 'laziness' & - uwa & elehuwa & 'laziness' \\
b. bozar 'marketplace' & - uwa & bozoruwa & 'cheap' \\
c. kesa & 'raw' & - uwa & keseluwa & 'raw(ness)' \\
d. & b $^{\mathrm{h}} \mathrm{vl}$ 'daze' & $-\mathrm{uwa}$ & $\mathrm{b}^{\mathrm{h}}$ uluwa & 'mislead'
\end{tabular}

The pattern observed above shows that when /-iya/ and /-uwa/ trigger harmony, /a/ alters to either [e] or [o], depending on the [ \pm Back] value of the rootinitial vowel. /a/-raising alongwith front harmony is the combined result of two processes.

In the kind of exceptional /a/-raising demonstrated by the presence of preceding mid stem vowels, the stem vowel ([-Low, - Back $]$ or $[-$ Low, + Back $])$ determines the $[ \pm$ Back] feature that $/ \mathrm{a} /$ might assume, so that it becomes $[+\mathrm{ATR}]$ ([e] or [o]). It is clear from this behaviour that the stem initial vowel is responsible for initiating a type of progressive front harmony, where the triggers /-iya/ and / $-\mathrm{uwa} /$, provide the morphological environment for this exceptional Front/Back harmony. The highlight of this process is, again, that this morpheme-specific $[ \pm$ Back] harmony focuses on a specific domain, which includes the vowel in the immediately following syllable of the trigger.

\section{Background to exceptional phenomena in the generative literature}

In recent theoretical discussion in the OT framework, there has been considerable interest in the way exceptional morphological interferences in phonology can be modelled (Pater 2000; Anttila 2002; Inkelas and Zoll 2003). It is of special interest in an OT framework where all constraints are universal and individual grammars are a result of permutation of these constraints. The interest then, lies in how morphologically conditioned phonological 'aberrations' can be handled in an OT approach. In the co-phonology approach 
of Antilla (2002), morphemes select their own ranking from a set of partially ordered constraints. Accordingly, only constraints that are unranked in the grammar can have lexically specified rankings. I will not go into the details of the co-phonology approach (cf. Antilla 2002 and Inkelas and Zoll 2003 for an elaboration of the framework, and Pater 2000, 2006, for arguments against the constraint ranking approach and in favour of constraint indexation). Again among the diacritic approaches, the ones favouring faithfulness constraint indexation are many and varied (e.g. Fukuzawa 1999; Itô and Mester 1999; 2001; Kraska-Szlenk 1997, 1999; Benua 2000; Alderete 2001). It has been argued that morpho-phonological processes are the result of the grammar at large. The indexation of Faithfulness constraints only was supposed to lend force to the argument that such grammar dependent processes have manifest limits on their range of occurrences (e.g. Benua 1997; Itô \& Mester 1999; Alderete 2001). It was argued that lexical indexation can pose limitations to the scope and extent of exceptional occurrences simply because of its restriction on the indexation of markedness constraints. Therefore Faithfulness only indexation would lead to languages which could not vary in the markedness patterns in its repertoire of exceptional processes.

\subsection{Constraint Indexation and morphologically conditioned exceptions in phonology}

Pater (2006) shows that most of the problems tackled in morpheme specific constraint ranking, as well as Faithfulness-only constraint indexation theories, can be analysed in terms of constraint indexation of both markedness and Faithfulness constraints. At the same time, however, the fact that exceptional triggering or blocking by morphemes is never an unbounded phenomenon, is only predicted by lexically indexed constraints. Constraint indexation is of special relevance in this paper because the predicted 'local' behaviour of morphemically indexed constraints is borne out in the exceptional data of Assamese. In the constraint indexation approach, morphemes that trigger a process are indexed for a lexically specific faithfulness or markedness constraint. It is assumed that these indexed constraints are cloned from already existing constraints, which are ranked lower in the hierarchy.

\subsection{An analysis of exceptionality in Assamese}

'Locality' or the application of a phonological process to a certain smallest possible domain is of special relevance in this paper. In Assamese, the two morphemes /-iya/ and /-uwa/ exceptionally trigger harmony in the otherwise opaque vowel /a/. This kind of triggering behaviour is exceptional, as it is 
confined only to these two morphemes, but it is also systematic: /a/ systematically changes to /o/ only when it is adjacent to the harmony triggering morpheme, i.e. if / $\mathrm{a} /$ does not occur in immediate proximity to the triggering vowel, the fact that it does not harmonise can be captured by a locally applicable markedness constraint to Assamese. The constraint which I propose to be active here is the indexed version of the contextual markedness constraint $*[-\mathrm{ATR}][+\mathrm{ATR}]_{\mathrm{L} 1}$.

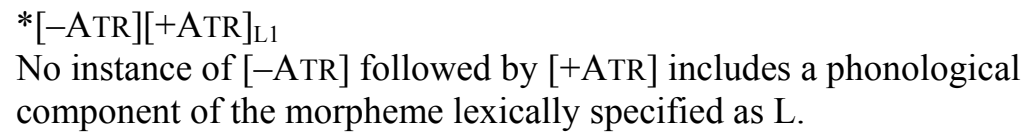

The locality convention manifests itself in this constraint in the form of a condition on the position of violation of this constraint. This constraint is violated only in the absolutely adjacent syllabic position of the triggering morpheme specified as L1. Any further instantiations of [-ATR][+ATR] are not under the jurisdiction of this constraint. The full ranking of Assamese exceptional triggering is given below in (21) and the corresponding tableau exemplifying the analysis is in (22):

$$
\begin{aligned}
& \text { Ranking: } *[-\mathrm{ATR}][+\mathrm{ATR}]_{\mathrm{L} 1}>>\text { IDENT }[\mathrm{Low}]>>*[-\mathrm{ATR}][+\mathrm{ATR}] \\
& >>*[+\mathrm{ATR}-\mathrm{High}]>>\text { IDENT[ATR }]
\end{aligned}
$$

Indexed morphemes in the Lexicon: /-iya/ ${ }_{\mathrm{L} 1} /-\mathrm{uwa} / \mathrm{L}_{1}$

\begin{tabular}{|c|c|c|c|c|c|}
\hline $\begin{array}{l}\text { Input: } \\
\text { lm r r/+/iya/L1 }\end{array}$ & $\begin{array}{l}*[-\mathrm{ATR}] \\
{[+\mathrm{ATR}]_{\mathrm{L} 1}}\end{array}$ & $\begin{array}{l}\text { [DENT } \\
\text { [Low] }\end{array}$ & $\begin{array}{l}*[-\mathrm{ATR}] \\
{[+\mathrm{ATR}]}\end{array}$ & $*[+$ ATR-High $]$ & IDENT [ATR] \\
\hline a. $\mathrm{m}$ riya & $* !$ & & $*$ & & \\
\hline b. & & * & & * & * \\
\hline c. moriyo & & **! & & ** & ** \\
\hline
\end{tabular}

/a/ harmonises in the presence of /-iya/

The lexically indexed constraint $*[-\mathrm{ATR}][+\mathrm{ATR}]_{\mathrm{L} 1}$ penalises a sequence where $[\mathrm{a}]$ is followed by the triggering [i]. Note that the constraint $*[-\mathrm{ATR}][+\mathrm{ATR}]_{\mathrm{L} 1}$ does not refer to the entire morphemic sequence of /-iya/ and /-uwa/, but only to a portion of it. (23)-a. is ousted because it violates the highly ranked lexically indexed constraint. The choice between the two remaining candidates (23)-b. and c. is determined by the faithfulness constraint IDENT[Low] which is violated twice by the failed candidate in (23)-c. In the tableau below, I show how this 
constraint hierarchy works when there are two instances of /a/ in the input. The tableau below shows that $*[-\mathrm{ATR}][+\mathrm{ATR}]_{\mathrm{L} 1}$ inhibits occurrences of $[-$ ATR $][+$ ATR $]$ only in the minimal domain.

Local alternation of /a/ when followed by /iya/ or /uwa/

\begin{tabular}{|c|c|c|c|c|c|}
\hline $\begin{array}{l}\text { Input: } \\
\text { /alax/+/uwa/L1 }\end{array}$ & $\begin{array}{l}*[-\mathrm{ATR}] \\
{[+\mathrm{ATR}]_{\mathrm{L} 1}}\end{array}$ & $\begin{array}{l}\text { [DENT } \\
\text { [Low] }\end{array}$ & $\begin{array}{l}*[-\mathrm{ATR} \\
{[+\mathrm{ATR}]}\end{array}$ & $\begin{array}{l}*[-\mathrm{Higl} \\
+\mathrm{ATR}]\end{array}$ & $\begin{array}{l}\text { IDENT } \\
\text { [ATR] }\end{array}$ \\
\hline a. alaxuwa & $* !$ & & * & & \\
\hline b. $\mathscr{*}$ aloxuwa & & $*$ & * & $*$ & $*$ \\
\hline c. oloxuwa & & $* * !$ & & $* *$ & ** \\
\hline
\end{tabular}

This tableau shows the markedness requirement of the exceptional trigger /uwa/, i.e. its local application. The indexed constraint $*[-\mathrm{ATR}][+\mathrm{ATR}]_{\mathrm{L} 1}$ does not apply to the initial /a/ of the stem /alax/. (24)-a violates the top ranked *[-

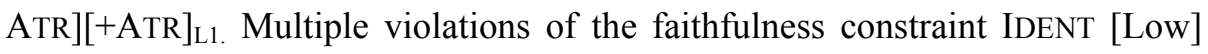
leads to the disqualification of the candidate (24)-c.

I now move on to discuss exceptional front harmony in Assamese, where a completely innovative Front/Back harmony is triggered by the presence of the /-iya/ and /-uwa/ morphemes, without itself undergoing any change.

\subsection{Exceptional front harmony in Assamese: emergent and local}

As discussed in section 2.3, exceptional triggering in Assamese also involves simultaneous changes of other features, i.e. it is not only the [-ATR] quality of the mid vowel which changes, but also the $[ \pm$ Back] quality of the vowel $/ \mathrm{a} /$. When there are no preceding vowels in the presence of /-iya/ and /-uwa/ triggers, /a/ assumes its own inherent [+Back] quality while adapting itself to a raised $[+$ ATR $]$ value. Therefore, IDENT $[ \pm$ Back $]$ remains unviolated in such circumstances, as shown by the tableau below:

(25) $/ \mathrm{a} /$ is faithful to IDENT[+Back] when it is the stem-initial vowel

\begin{tabular}{|c|c|c|c|c|c|c|}
\hline $\operatorname{mar} /+/ \mathrm{iya} / \mathrm{L} 1$ & $\begin{array}{l}*[-\mathrm{ATR}] \\
{[+\mathrm{ATR}]_{\mathrm{L} 1}}\end{array}$ & $\begin{array}{l}\text { IDENT } \\
{[ \pm \text { Back }}\end{array}$ & [DEN] & $\begin{array}{l}{[- \text { ATR }} \\
+ \text { ATR }]\end{array}$ & $\begin{array}{l}*[- \text { Hig } \\
+ \text { ATR }]\end{array}$ & $\begin{array}{l}\text { h[DEN] } \\
{[\text { [ATR] }}\end{array}$ \\
\hline a. mariya & $* !$ & & & * & & \\
\hline b. $\nabla^{\top}$ & & & * & & * & * \\
\hline c. meriya & & *! & * & & $*$ & * \\
\hline
\end{tabular}


The example above also shows that the $[ \pm \mathrm{Back}]$ specification of the low vowel is not influenced by the $[ \pm$ Back] quality of the triggering vowel. The vowel /a/ retains its $[+\mathrm{Back}]$ value despite the fact that the triggering morpheme is [Back]. IDENT[+Back] is higher ranked than IDENT[Low] as faithfulness to the [Back] value of $/ \mathrm{a} /$ is substantially more important than faithfulness to the [Low] value ${ }^{8}$. This accounts for the failure of candidate (25)-c where a [Back] value alteration occurs.

However, this is the straightforward case of /a/-raising. The second type of exceptionality pertains to the raising of $/ \mathrm{a} /$ to the $[ \pm$ Back] vowel quality of the preceding mid vowel, such that, if the preceding mid vowel is [-Back], /a/ is also [-Back] and vice versa. This phenomenon, which can be called 'emergent front harmony"9 only influences the immediately following vowel, thereby exhibiting a local process. This kind of exceptionality is also strictly limited to the domain of a bisyllabic root (also recall section 2.1 where /a/-raising in general does not affect trisyllabic domains).

To analyse these cases where the [ \pm Back] specifications change as a result of a stem-initial vowel, I will propose a sequential markedness constraint which requires the agreement of $[ \pm$ Back] values in the smallest possible domain of the root. Before presenting a formal analysis, we have to present a modification of our understanding of the locus of violation that was postulated in the preceding section.

The trigger of exceptional /a/-raising was the $/-\mathrm{i} /$ or $/-\mathrm{u} /$ portion of the morphemes /-iya/ and /-uwa/, but in the case of emergent front harmony, /-iya/ and /-uwa/ only provide the environment for the application of this constraint. /iya/ and /-uwa/ do not provide a 'direct' phonological motivation for the occurrence of front harmony, at least not in the same way that it provides the phonological factor for the occurrence of /a/-raising. Taking the instance of /elehuwa/ again, the $[+$ Back $]$ feature of $/ \mathrm{u} /$ in $/-\mathrm{uwa} /$ cannot be held responsible for the spreading of [-Back] features in the root of /elehuwa/. This cannot be dissimilation either, given that there are derived lexical items like / $\mathrm{d}^{\mathrm{h}}$ emeliya/ (cf (18) b.). Obviously then, the spreading of $[ \pm$ Back $]$ features in the root seems to have 'nothing to do' with the phonological components of the morphological environment which provides for this exceptional process. There perhaps need not always be an intimate phonological motivation for morpheme-specific phonological phenomena, but whenever there is one, it undoubtedly leads to a tighter and unified analysis. The fact that there is no such clear-cut motivation in exceptional front harmony gives way to some other insights which would not have otherwise caught our attention. Exceptional front harmony involves two processes, one is /a/-raising and consequently [ATR] spreading, the other is front harmony. What we have not stressed till now is the special status of the vowel most adjacent to the exceptional morpheme. In this analysis, I suppose that the 
dual exceptionality of the kind encountered in Assamese is because the vowel most adjacent to the exceptional morpheme is specially licensed to undergo exceptional behaviour. Therefore, the constraint responsible for exceptional front harmony needs to be effective in prohibiting non-adjacent segments from the domain of exceptional front harmony. The constraint is formulated as below:

$$
\text { *[-Back -High }][+ \text { Back }- \text { High }] \text { iyd }{ }_{\mathrm{L} 1}
$$

Assign a violation mark to the minimal string containing a [-Back High] vowel followed by a [+Back -High] vowel, only if a portion of the string is the vowel which is adjacent to a morpheme indexed as $\mathrm{L}_{1}$

I assume that the constraint $*[-$ Back - High $][+$ Back - High $]$ is a universal constraint which drives Front/Back harmony. However, this constraint exceptionally selects only those lexical items which have an /-iya/ or a /-uwa/ suffix. The constraints $*[-\mathrm{ATR}][+\mathrm{ATR}]_{\mathrm{L} 1}$ and $*[-\mathrm{Back}-\mathrm{High}][+\mathrm{Back}-\mathrm{High}]_{\mathrm{L} 1}$ are ranked together and any optimal candidate has to respect both of these constraints.

\begin{tabular}{|c|c|c|c|c|c|c|}
\hline $\begin{array}{l}\text { Co-dependent } \\
\text { elah/+/uwa/L1 }\end{array}$ & $\begin{array}{l}* \text { ATR }][+f(-\mathrm{ATR}] \\
{[+\mathrm{ATR}]}\end{array}$ & 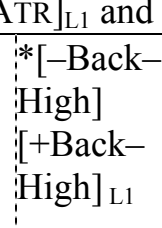 & $\begin{array}{l}\text { * } \\
{[\text { [DENT }} \\
{[-B a c k]}\end{array}$ & $\begin{array}{l}-\mathrm{High}][+\mathrm{+} \\
\text { IDENT } \\
{[+ \text { Back }]}\end{array}$ & $\begin{array}{l}\text { Back - } \\
\text { IDENT } \\
][\text { Low }]\end{array}$ & 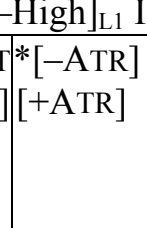 \\
\hline a. clahuwa & $* !$ & & & & & $*$ \\
\hline b. elahuwa & * & ! ! & & & & $*$ \\
\hline c. $\nabla^{\circ}$ ehuwa & & & & * & * & \\
\hline d. olohuwa & & 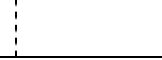 & ! ! & & * & \\
\hline e. elohuwa & & ! & : & & * & \\
\hline f. olehuwa & & & ! ! & * & * & \\
\hline
\end{tabular}

The tableau in (27) shows how constraint indexation can satisfactorily capture two processes which are indexed to the same morpheme. The selected candidate [elehuwa] satisfies the highly ranked lexically indexed markedness constraint $*[-$ Back $-\mathrm{High}][+ \text { Back }-\mathrm{High}]_{\mathrm{L} 1}$. It also simultaneously satisfies *[$A T R][+A T R]_{L 1}$. Both these processes require the same environment, i.e. exceptional triggering by the vowels in /-iya/ and /-uwa/, but they do not 
contravene the principle of locality that constraint indexation espouses. Both the processes of exceptional /a/-raising and Front/Back harmony are concentrated on the absolutely adjacent syllable or 'minimal string'. The evaluation shows how this constraint ranking prohibits candidates (27)-b and (27)-e because they violate *[-Back -High][+Back -High $]_{\text {L1}}$. Candidates (27)-d and (27)-f are barred from being selected in this evaluation because of their multiple violations of IDENT[-Back]. The tableau below shows an input which contains a /CoCa-/ sequence.

\begin{tabular}{|c|c|c|c|c|c|c|}
\hline \multicolumn{7}{|c|}{ Co-dependent $*[-\mathrm{ATR}][+\mathrm{ATR}]_{\mathrm{L} 1}$ and $*[-$ Back $-\mathrm{High}][+ \text { Back }-\mathrm{High}]_{\mathrm{L} 1}$} \\
\hline pozar/+/uwa/L1 & $\begin{array}{l}*[-\mathrm{A}] \\
{[+\mathrm{A}]_{\mathrm{L} 1}}\end{array}$ & {$\left[\begin{array}{l}{[- \text { Back-High }]} \\
{[+ \text { Back-High }]_{L}}\end{array}\right.$} & {$\left[\begin{array}{l}\text { IDENT } \\
{[- \text { Back }}\end{array}\right]$} & $\begin{array}{l}\text { IDENT } \\
{[+ \text { Back }]}\end{array}$ & $\begin{array}{l}\text { IDENT } \\
\text { [Low] }\end{array}$ & $\begin{array}{l}*[-\mathrm{ATR} \\
+\mathrm{ATR}]\end{array}$ \\
\hline a. bozaruwa & *! & & & & & * \\
\hline b. bozaruwa & *! & & & & & * \\
\hline c. bozoruwa & & & & & * & \\
\hline d. bezeruwa & & : & & $* ! *$ & * & \\
\hline e. bozeruwa & & 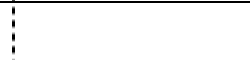 & & $* !$ & * & \\
\hline f. bezoruwa & & ! ! & & * & * & \\
\hline
\end{tabular}

The constraint hierarchy is able to generate the right output [bozoruwa] because the selected output neither violates * $[-$ Back - High $][+ \text { Back }- \text { High }]_{\mathrm{L} 1}$ nor * $[-$ ATR][+ATR]. All the other candidates incur fatal violations of either the two high ranking constraints or the constraint demanding faithfulness to the $[ \pm$ Back $]$ values.

The modification of the locality principle in exceptional morphemic triggering shows that only a segment adjacent to a triggering morpheme is the subject of the exceptional process. The difference in Assamese is that the adjacent segment ends up bearing two exceptionalities, and one of them is not the direct result of the phonological properties that the exceptional morpheme bears. Despite this modification in our approach, we have been able to save the crucial generalisation that exceptional morphemic triggering involves as minimal a domain as possible.

Although locality is salvaged, there is another fundamental tenet of OT which is undermined by the indexed markedness constraint * [-Back High $][+ \text { Back }-\mathrm{High}]_{\mathrm{L} 1}$. The constraint demanding front harmony only in the root subverts a central tenet espoused in OT (McCarthy and Prince, 1993) that FAITH ROOT always outranks FAITH AFFIX. In effect therefore, the caveat that Pater (2006) had mentioned about the potential of lexically indexed morphemespecific constraints ability to subvert this 'universal' metaranking can be a real- 
ity. In fact, the data itself shows that front harmony applies to the root but fails to apply to the suffix. Although we are not yet certain whether this is something to be hailed as an achievement of morpheme-specific indexed constraints, it may be instructive to look at the possible reasons for this kind of exceptionality.

All Front/Back harmony systems are triggered from root outwards (see Kaun 1995 and Walker 2001 for a cross-linguistic survey) and emergent Front/Back harmony in Assamese falls in line with this universal pattern. The next question which confronts us is then why doesn't this exceptional front harmony not neutralise the Front/Back values of the suffixes /-iya/ and /-uwa/ as well? The reason lies in what we have been arguing for exceptional patterns all along that all exceptional patterns need to be local, affecting a minimal string, and in this case the minimal string comprises of the value of one root vowel only. This particular root vowel is the vowel adjacent to the exceptional triggering vowel, which is specially licensed to display exceptional behaviour. To recapitulate from the discussion in section 2.1 in this paper, the bisyllabic root is important to characterise the nature of exceptional occurrences in Assamese and these are the following: firstly, the domain of application of /a/-raising is always the bisyllabic root (see examples in (14)). Secondly, there is no /a/-raising when a / / is the final vowel of a trisyllabic word (the /a/ deletes itself in those cases). Finally, prefixes are ruled out from the domain of /a/-raising. Front harmony is locally applicable only to the $[ \pm$ Back $]$ values of the vowels of the root. All these combined factors keep out suffixes from the influence of the process of front harmony.

The surfacing of front harmony plays a significant role in emphasising the aspect of emergent unmarkedness that may be sometimes underscored by exceptional processes. The constraint demanding front harmony is operative in many harmony languages of the world. Given OT's architecture, it is only natural that the markedness constraint responsible for triggering front harmony in some languages is also present but not active in the constraint hierarchies of other unrelated languages. Therefore, the emergence of this unmarked pattern in the exceptional phonology of Assamese confirms the existence of The Emergence of the Unmarked (TETU, McCarthy and Prince 1994a) effects even in exceptional phenomena.

By restricting the exceptional process to a root domain only, the most prominent vowels are affected by the process. The universal tendency of the triggers of front harmony being in the root vowel also lends support to our account of emergent front harmony in Assamese as a process which abides by universal tendencies. It is perhaps in contexts like these that the metaconstraint FAITH ROOT >> FAITH AFFIX needs reconsideration. ${ }^{10}$ In a morphologically driven exceptional pattern, various factors pertaining to minimal domain and universally well-attested root outward harmony conspire to produce an output which fatally violates this particular metaconstraint. Hence, the metaconstraint 
though an useful constraint to refer to a lot of phonological processes which attest more faithfulness in roots and more neutralisation in affixes can lead to wrong predictions of cases where multiple factors converge to produce more faithfulness in affixes than in roots.

\subsection{Alternative theoretical approaches to morpho-phonemic alternations}

We can compare this derived environment domain with the processes of derived environments presented in Kiparsky (1993), Lubowicz (2003) and elsewhere. Taking as a case in point the most recent treatment of derived environment in Lubowicz, we can try to draw a parallel and see if we need a similar treatment of the processes discussed in this paper. To get away with the problem of blocking effects in DEE (Derived Environment Effects) Lubowicz conjoins the two constraints, so as to get the results which are seen only in a derived environment. Consequently, we can offer a Lubowicz-style conjoined constraint *[Back -High] \& IDENT (Low) >> IDENT (Back) solution to the problem described here. The problem with this constraint is that it still does not capture the absolutely morpheme-specific environment of Front harmony in Assamese. Pater (2006) argues that all morphologically derived environment domains can be analysed with the aid of constraint indextion. The added advantage of lexical indexation in morpheme specific phonology is that it offers a way of getting the results of some phonological processes, which are observed in a derived environment domain, yet morpheme-specific.

A theoretical approach which would founder with respect to the Assamese patterns of morpho-phonological interaction is that of cophonology, more specifically in the manner argued by Anttila (2002), one of the main proponents of the cophonology approach. Cophonology in general requires exceptionalities in the lexicon and morphology to be analysed with the aid of lexically specified rankings of constraints which are already present in the grammar. In this approach propagated by Anttila (2002) only pairs of constraints whose ranking is unspecified in the grammar can have lexically specified rankings. When a lexical item is unspecified for the respective ranking, then it would show variation. In the case of the exceptions of the emergent variety, no such pairing is possible. In these cases, a low ranked constraint supercedes all other Markedness and Faithfulness Constraints to assume precedence over them. Anttila (2002) also presents this model to establish a connection between exceptionality and variation, so that whenever the constraints are unranked the resultant output has the potential to vary either on the Markedness or on the Faithfulness count. This kind of variation is not attested in Assamese and therefore this attribute of Cophonology cannot be applicable to all instances of exceptionality in the grammar of languages. Further, as argued in Pater (2006), Anttila (2002) cannot ele- 
gantly capture local effects of constraints which are active in exceptional triggering and blocking.

\section{Vowel harmony in verbs}

Assamese does not allow the presence of [e] and [o] without a following /i/ or $/ \mathrm{u} /{ }^{11}$. In such a scenario, the result of harmony when the verbal root $/ \mathrm{rJ} /$ 'wait' 12 is suffixed with /-il/ is expected to be /roil/ (or maybe even /royil/ because of hiatus avoidance). The existence of the apparently impossible sequences / $\mathrm{rol} /$, $/ \mathrm{gol} /(\text { after the deletion of } / \mathrm{i} /)^{13}$, etc. is therefore unpredictable, given the phonological grammar of the language. The eventually occurring surface output forms /rol/ and /gol/ are realised with the harmonised segment /o/ even though the triggering segment /i/ has been deleted. I present a sample of the vowel harmony pattern displayed in verbs:

(29) Vowel harmony in the verbal paradigm

\begin{tabular}{|c|c|c|c|c|}
\hline Verbal root & ro'wait' & lo 'take' & $\mathrm{d}^{\mathrm{h}_{U}}$ 'wash' & $\mathrm{k}^{\mathrm{h}} \mathrm{a}$ 'eat' \\
\hline Past perfect & $\mathrm{i} 1+\mathrm{v} / \mathrm{i} / \mathrm{a} / \varepsilon$ & $\mathrm{il}+\mathrm{v} / \mathrm{i} / \mathrm{a} / \varepsilon$ & $\mathrm{i} 1+\mathrm{v} / \mathrm{i} / \mathrm{a} / \varepsilon$ & il $+u / i / a / \varepsilon$ \\
\hline & rolv & lolv & $\mathrm{d}^{\mathrm{h}} \mathrm{ulv}$ & $\mathrm{k}^{\mathrm{h}} \mathrm{alu}$ \\
\hline $2 \mathrm{P}($ fam $)$ & roli & loli & $\mathrm{d}^{\mathrm{h}} \mathrm{uli}$ & $\mathrm{k}^{\mathrm{h}} \mathrm{ali}$ \\
\hline $\begin{array}{l}2 \mathrm{P}(\text { ord }) \\
2 \mathrm{P}(\text { hon }) \& 3 \mathrm{P}\end{array}$ & rola & lola & $\mathrm{d}^{\mathrm{h}} \mathrm{ula}$ & $\mathrm{k}^{\mathrm{h}} \mathrm{ala}$ \\
\hline $2 \mathrm{Y}(\mathrm{non}) \mathrm{XJP}$ & role & lole & $\mathrm{d}^{\mathrm{h}} \mathrm{ul} \varepsilon$ & $\mathrm{k}^{\mathrm{h}} \mathrm{al} \varepsilon$ \\
\hline future & $\mathrm{im} / \mathrm{ib}+\mathrm{i} / \mathrm{a}+\boldsymbol{\jmath}$ & $\mathrm{im} / \mathrm{ib}+\mathrm{i} / \mathrm{a}+\boldsymbol{\jmath}$ & $\mathrm{im} / \mathrm{ib}+\mathrm{i} / \mathrm{a}+\mathbf{0}$ & $\mathrm{im} / \mathrm{ib}+\mathrm{i} / \mathrm{a}+\mathrm{o}$ \\
\hline $1 \mathrm{P}$ & rom & lom & $d^{\text {h }} u m$ & $\mathrm{k}^{\mathrm{h}} \mathrm{am}$ \\
\hline $2 \mathrm{P}(\mathrm{fam})$ & robi & lobi & $\mathrm{d}^{\mathrm{h}} \mathrm{ubi}$ & $\mathrm{k}^{\mathrm{h}} \mathrm{abi}$ \\
\hline $2 \mathrm{P}$ (ord) & roba & loba & $d^{\text {h }} u b a$ & $\mathrm{k}^{\mathrm{h}} \mathrm{aba}$ \\
\hline 2P(hon)\&3P & robo & lobo & $\mathrm{d}^{\mathrm{h}} \mathrm{ubo}$ & $\mathrm{k}^{\mathrm{h}} \mathrm{abo}$ \\
\hline
\end{tabular}

In the paradigms above, the [+high + ATR $]$ vowel /i/ always trigger a change in the preceding $[-\mathrm{ATR}]$ vowels $/ \varepsilon / / \mathrm{J} /$ and $/ \mathrm{U} /$. Verbs inflect in the following order:

$$
\text { Root }+ \text { Aspect }(\text { Perfective/Progressive })+\text { Tense }+ \text { Person }
$$

The pattern of inflection of the open monosyllables $/ \mathrm{d}^{\mathrm{h}} \mathrm{v}$ / 'wash' and $/ \mathrm{k}^{\mathrm{h}} \mathrm{a} /$ 'eat', deserves attention because only open monosyllables provide the context for vowel deletion. Therefore, only these monosyllables have been taken into 
consideration. Note that the monosyllabic verbs like /ro/ 'wait' appear to inflect for their future and past perfect forms without the presence of the harmonytriggering vowel by undergoing the alternation that the deleted vowel triggers. Therefore, in the past perfect and future forms of all the verbal forms above, the vowel /i/ is deleted, such that the initial vowels in $/ \mathrm{im} /, / \mathrm{ib} / \mathrm{and} / \mathrm{il} /$ are left invisible after inflection. But these altered forms exist in the verbal morphology as a result of vowel harmony triggered by the underlying presence of $/ \mathrm{i} /$. However, the paradigm in (29) is not representative of the entire verbal morphology of Assamese. In other words, /i/ deletion under hiatal conditions is not attested across the board in the verbal morphology of the language. In the following paradigm, as a result of affixation of $/-$ is/, the perfective suffix, there is no deletion or epenthesis.

\begin{tabular}{|c|c|c|c|}
\hline Root & $\begin{array}{l}\mathrm{k}^{\mathrm{h}} \mathrm{a}+\text { is }+ \\
\mathrm{v} / \mathrm{\jmath} / \mathrm{a} / \varepsilon\end{array}$ & $\begin{array}{l}\mathrm{r} \supset+\text { is }+ \\
\mathrm{v} / \mathrm{o} / \mathrm{a} / \varepsilon\end{array}$ & $\begin{array}{l}\mathrm{d}^{\mathrm{h}} \mathrm{v}+\text { is }+ \\
\mathrm{v} / \mathrm{\jmath} / \mathrm{a} / \varepsilon\end{array}$ \\
\hline \multicolumn{4}{|c|}{ Present Progressive } \\
\hline $1 \mathrm{P}$ & $\mathrm{k}^{\mathrm{h}}$ aisu & roisu & $\mathrm{d}^{\mathrm{h}}$ uisu \\
\hline $\begin{array}{l}2 \mathrm{P}(\text { fam }) \\
2 \mathrm{P} \text { (ord) }\end{array}$ & $\mathrm{k}^{\mathrm{h}}$ aiso & roiso & $\mathrm{d}^{\mathrm{h}}$ uiso \\
\hline \multirow[t]{4}{*}{ 2P(hon)\&3P } & $\mathrm{k}^{\mathrm{h}}$ aisa & roisa & $\mathrm{d}^{\mathrm{h}}$ uisa \\
\hline & $\mathrm{k}^{\mathrm{h}} \mathrm{ais} \varepsilon$ & rois $\varepsilon$ & $\mathrm{d}^{\mathrm{h}} u$ is $\varepsilon$ \\
\hline & $\mathrm{k}^{\mathrm{h}} \mathrm{a}+$ is + & $\mathrm{ro}+\mathrm{is}+$ & $\mathrm{d}^{\mathrm{h}} \mathrm{v}+$ is + \\
\hline & $\mathrm{il}+\mathrm{v} / \mathrm{\jmath} / \mathrm{a} / \varepsilon$ & $\mathrm{i} 1+\mathrm{v} / \mathrm{\jmath} / \mathrm{a} / \varepsilon$ & $\mathrm{i} 1+\mathrm{v} / \mathrm{o} / \mathrm{a} / \varepsilon$ \\
\hline \multicolumn{4}{|l|}{ Past- } \\
\hline Progressive & $\mathrm{k}^{\mathrm{h}}$ aisilu & roisilu & $\mathrm{d}^{\mathrm{h}}$ uisilu \\
\hline $\begin{array}{l}1 \mathrm{P} \\
\mathrm{P}(\mathrm{fam})\end{array}$ & $\mathrm{k}^{\mathrm{h}} \mathrm{aisili}$ & roisili & $\mathrm{d}^{\mathrm{h}}$ uisili \\
\hline $2 \mathrm{P}($ ord $)$ & $\mathrm{k}^{\mathrm{h}}$ aisila & roisila & $\mathrm{d}^{\mathrm{h}}$ uisila \\
\hline 2P(hon)\&3P & $\mathrm{k}^{\mathrm{h}}$ aisile & roisile & $\mathrm{d}^{\text {h }}$ uisile \\
\hline
\end{tabular}

The set of examples above show that the morphological extension /-is/ does not require hiatus resolution. The constraint on hiatus resolution is violated by the verbal derivations produced as a result of the addition of $/-$ is/.

\subsection{Hiatus resolution - deletion and epenthesis}

It is a well-observed phenomenon that segments may be either deleted or inserted and thereby link two adjacent segments, which may be present at the 
edges of a morphological domain. It is therefore only natural that hiatus avoidance is present in the phonology of Assamese, independent of vowel harmony. Apart from the verbal paradigm discussed above, hiatus avoidance ${ }^{14}$ is robust in Assamese derived forms. Some examples from the nominal paradigm of Assamese are presented below:

$$
\begin{aligned}
& \text { [-ATR] initial suffixes } \\
& \text { Root Ergative Accusative Dative Genitive Locative Instrumental } \\
& / \varepsilon / \quad / \mathrm{k} / \quad / \mathrm{loi} / \quad / \mathrm{r} / \quad / \mathrm{t} / \quad / \mathrm{r} /
\end{aligned}
$$

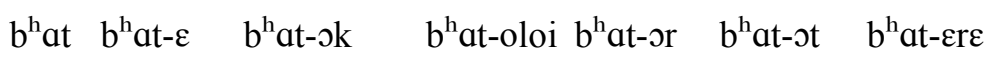

$$
\begin{aligned}
& \text { ma ma-ye ma-k ma-loi ma-r ma-t ma-re }
\end{aligned}
$$

These examples show that hiatus avoidance ${ }^{15}$ is indeed present as a strategy in the morpho-phonology of Assamese when morphology provides the context of a juncture. Hiatus avoidance measures like epenthesis kick in to preserve the ideal phonological shape of a morpho-phonological word, when morphology provides the context of a juncture. There are some other examples from adjective formation where the epenthetic element may be /1/ or $/ \mathrm{r} /$ as shown in the examples below:

(33) Epenthesis in adjective formation
a. kesa 'raw' -uwa keseluwa 'raw(ness)'
b. misa 'false' -uwa misoliya 'liar'
c. deka 'young'-uwa dekeruwa 'young-ish'

As argued in the literature of OT, hiatus need not be the constraint involved in the analysis of all such instances. A requirement on Onsets can easily account for the cases shown in (32) and (33). The following two are the contending constraints

*Hiatus

"Assign a violation mark to heterosyllabic vocalic sequences"

\section{ONSET}

"Syllables must have Onsets"

The constraint *HIATUS is a prohibition against heterosyllabic vowel-vowel sequences. As the example from the nominal paradigm show, hiatus is normally resolved by inserting an epenthetic element. Epenthesis is possible because of the ranking *HIATUS $>>$ DEP. It may be noted here, that the requirement of 
ONSET can also lead to the same results. Hence our tableaux reflects our indecision as to the choice of the proper constraint at this point (This problem is again dealt with immediately in (38) - (40) where the untenability of ONSET for all cases of hiatus avoidance is discussed ). The two tableaux below show how epenthesis surfaces in Assamese, in the light of the examples from the case extensions.

*Hiatus $>$ DEP
\begin{tabular}{|l|l|l|l|}
\hline ma $+\varepsilon$ & MAX & $*$ HiATUS/ONSET & DEP \\
\hline a. ${ }^{\circ}$ may $\varepsilon$ & & & $*$ \\
\hline b. ma $\varepsilon$ & & $* !$ & \\
\hline c. $\mathrm{ma}$ & $* !$ & & \\
\hline
\end{tabular}

*Hiatus $>>$ DEP
\begin{tabular}{|l|l:l|l|}
\hline ma $+\mathrm{k}$ & MAX & $*$ HiATUS/ONSET & DEP \\
\hline a. maok & & $* !$ & \\
\hline b. ${ }^{-}$mak & & & \\
\hline
\end{tabular}

Unlike the cases discussed above, instead of resolving hiatus by inserting an epenthetic element, morphemes in the verbal paradigm present exceptions to this normal routine of syllabification. The vowel /i/ triggers regular harmony in the verbal paradigm, but a few morphemes show quirks in the way hiatus is resolved - the morphemes $/-\mathrm{i} / /$ and $/-\mathrm{im} /$ trigger vowel deletion and the morpheme $/$-is/ prefers hiatus over either epenthesis or deletion, in blatant violation of all constraints demanding hiatus resolution. In the light of this, a discussion of the alternatives and their untenability is also in order.

In OT, syllabification has been shown to be the outcome of constraints like ONSET and DEP to the exclusion of constraints which make demands on proper syllabic shape like that of *HIATUS, which are deemed superfluous. We try to analyse the consequences of an alternative analysis which does not depend on *HiATUS. Insofar as the following example in (33) with an epenthetic element $/ 1 /$ is concerned, a constraint which does not include *HIATUS does not seem to be counter-productive. 
of

\begin{tabular}{|l|l|l|l|}
\hline$/$ ro/+/ila/ & ONSET & MAX & DEP \\
\hline \hline a. $\odot$ rola & & $*$ & \\
\hline b. roila & $* !$ & & \\
\hline c. ${ }^{\circ}$ royila & & & $*$ \\
\hline
\end{tabular}

ONSET is required in this hierarchy as the exclusion ONSET will produce */misoiya/. However, in the evaluation of the two candidates which exhibit exceptional syllabification, this constraint set falters and leads to the selection of the wrong output candidates.

Analysis of deletion with ONSET $>>$ MAX $>>$ DEP

\begin{tabular}{|l|l|l|l|l|}
\hline$/ \mathrm{ro} /+/$ is $_{13} /+/$ ila/ & MAX $_{\text {L3 }}$ & ONSET & MAX & DEP \\
\hline \hline a. Oroisila & & & & $*$ \\
\hline b. ${ }^{\circ}$ royisila & & & $*$ & \\
\hline c. rosila & $* !$ & & $*$ & \\
\hline
\end{tabular}

Another instance where ONSET is unable to lead to the actually occurring output if it is ranked above MAX and DEP, is when an indexed MAX L constraint is ranked highest This is shown in the evaluation of the candidate /roisila/ where /-is/ prefers a hiatal context in the site of the juncture instead of hiatus resolution. The ranking of ONSET $>>$ DEP pathologically selects /royisila/. The indexed constraint MAX L3 fails to give a verdict in this case.

Failure of $\mathrm{MAX}_{\mathrm{L} 3}>>$ ONSET $>>$ MAX $>>$ DEP ranking

This

\begin{tabular}{|l|l|l|l|}
\hline misa + iya & ONSET & MAX & DEP \\
\hline a. misoiya & $* !$ & & \\
\hline b. misoliya & & & $*$ \\
\hline c. misoya & & $* !$ & \\
\hline
\end{tabular}

discussion

has brought forth significant empirical motivation behind the proposal to motivate *HIATUS. Therefore, in the following sections we will proceed 
with an analysis where *HIATUS is used as a constraint to analyse instances of epenthesis in Assamese.

\section{2. /i/deletion in the verbal paradigm}

In this paper it is shown that two set(s) of morphemes in the verbal paradigm idiosyncratically make one of the two choices - in one, the morphemes /-il/ /$\mathrm{ib} /$ and /-im/ opt for unmarked syllabification by choosing deletion over epenthesis and in the second case the morpheme /-is/ arbitrarily chooses a marked syllabification where the addition of /-is/ results in onsetless syllables. Before providing a complete analysis of the exceptions discussed till now, I will present the constraints which are required for an analysis of this pattern of deletion in Assamese verbs. The type of deletion and subsequent fusion of a featural quality is also known as coalescence. The constraint which prohibits coalescence in OT is the following:

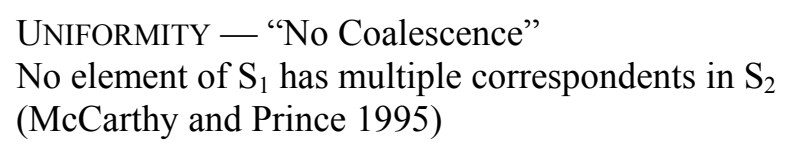

This faithfulness constraint requires an output segment to correspond to only one input segment. The constraint UNIFORMITY is violated by those segments in which multiple elements in the input representation are fused in the output. In the evaluation in Assamese it will be shown that this constraint will be violated by sequences where the alternation is the one as following:

$$
/ \mathrm{r}_{1} \mathrm{o}_{2} /+/ \mathrm{i}_{3} 1_{4} / \rightarrow / \mathrm{r}_{1} \mathrm{o}_{2,3} 1_{4} /
$$

In this type of alternation $/ \mathrm{o} /$ and $/ \mathrm{i} /$ are fused in the output to be realised as $/ \mathrm{o} /$. Another faithfulness constraint which is relevant in the analysis of the type of deletion encountered here is the IDENT $\mathrm{I} \rightarrow \mathrm{O}[\mathrm{F}]$ constraint, proposed in Pater (1999). This constraint was proposed to deal with the asymmetry (as opposed to MAX constraints, where MAX[F] penalises deletion and DEP penalises insertion) in the IDENT family of constraints proposed in the correspondence model of faithfulness (McCarthy and Prince 1995). In the IDENT family of constraints an IDENT[F] constraint can be violated only in the presence of a segment's feature value in the output, and not in its absence. The faithfulness constraint required to prohibit featural deletion in Assamese is IDENT $\mathrm{I} \rightarrow \mathrm{O}[\mathrm{ATR}]$, which is stated below:

$$
\text { IDENT I } \rightarrow \text { O [+ATR }]
$$


Output correspondents of a feature specified as [+ATR] must be [+ATR]

This faithfulness constraint will evaluate the faithfulness of [+ATR] values in the output. In other words, an output representation with the deletion of a corresponding input [+ATR] value would incur a violation mark.

Again we will see that an indexed *HIATUS constraint determines the emergence of syllabification patterns which can be considered exceptional in Assamese. I formulate this lexically specified faithfulness constraint as below:

\section{Constraint lexicon}

$*^{*}$ HIATUS $_{\mathrm{L} 2}$

$/ \mathrm{il} / / \mathrm{ib} / / \mathrm{im} /$

"Avoid heterosyllabic vocalic sequences"

The analysis to be presented holds that ${ }^{*}$ HIATUS $_{\text {L2 }}$ is crucial in determining the output candidate when the triggering segment is deleted in morpheme-specific surface well-formedness constraints.

*HIATUS $_{\mathrm{L} 2}$ and faithfulness of the deleted feature

\begin{tabular}{|c|c|c|c|c|}
\hline $\mathrm{rJ} /+/ \mathrm{im} / \mathrm{L} 2$ & 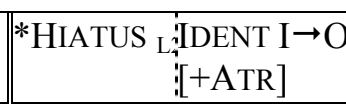 & UNIFORM & $\begin{array}{l}\text { I }[-\mathrm{ATR}] \\
{[+\mathrm{ATR}]}\end{array}$ & *HIATUS \\
\hline a. roim & *! & & * & \\
\hline b. roim & *! & & & * \\
\hline c. rom & ! ! & & & \\
\hline d. rom & $\vdots$ & * & & \\
\hline
\end{tabular}

In the tableau above, ${ }^{*}$ HIATUS ${ }_{\text {L2 }}$ effectively bars the candidates (45)-a and (45)$\mathrm{b}$ from being the winners in the evaluation. In the absence of an indexed constraint, the candidate in (45)-b, [roim] would offer the most competition as it satisfies UNIFORM which the candidate now selected as a result of satisfying the highest ranking *HIATUS $\mathrm{L}_{2}$ does not. IDENT I $\rightarrow \mathrm{O}$ [+ATR] prohibits (45)-c from emerging as the winner as it does not preserve the [+ATR] quality of an input segment.

(46) *HiAtus $\mathrm{L}_{2}$ drives hiatus resolution in some parts of the verbal morphology

\begin{tabular}{|l||l:l|l|l|l|}
\hline ro/+/-il-a/L2 & $*$ HIATUS L2 & $\begin{array}{l}\text { IDENT } \\
\mathrm{I} \rightarrow \mathrm{O}[\mathrm{ATR}]\end{array}$ & UNIFORM & $\begin{array}{c}*[-\mathrm{ATR}] \\
{[\mathrm{ATR}]}\end{array}$ & *HIATUS \\
\hline \hline a. roila & $* !$ & & & & $*$ \\
\hline b. roila & $* !$ & & & $*$ & $*$ \\
\hline c. rola & & $* !$ & & & \\
\hline d. ${ }^{\circledast}$ rola & & & $*$ & & \\
\hline
\end{tabular}


By evaluating another candidate which has a suffix of the shape /VCV/, we can see that the same process applies to all morphemes indexed as $\mathrm{L}_{2}$. While hiatus resolution drives deletion, requirements of featural faithfulness result in the expression of the morpheme's [+ATR] feature on the preceding vowel. In the tableau below, while the high-ranking *HIATUS ${ }_{\mathrm{L} 2}$ requires vowel deletion, the constraint IDENT I $\rightarrow \mathrm{O}[\mathrm{ATR}]$ preserves the [ATR] feature in the output form, resulting in the optimal candidate which satisfies both constraints.

In the evaluation in the tableau above, the resultant output form /rola/ is a product of the combined forces of IDENT I $\rightarrow$ O [ATR] and *HIATUS L2. Candidates (46)-a and (46)-b violate *HiATUS $\mathrm{L}_{2}$. Candidate (46)-c violates IDENT $I \rightarrow O$ [ATR], which demands faithfulness to the feature value of the deleted segment, resulting in a failed candidate.

On one hand, /a/-raising is one the factors which stands out in the morpheme triggered exceptional process of Assamese, and on the other hand, /a/ does not undergo alternation as a result of exceptional hiatus resolution in the verbal paradigm. The segment $/ \mathrm{i} /$ is deleted altogether without any corresponding coalescence or preservation of the value of [+ATR] of the deleted segment. The tableau below shows that a high-ranking IDENT [low] prevents any change in the feature specification of $/ \mathrm{a} /$.

\section{Inertness of /a/ under morpheme deletion}

\begin{tabular}{|c|c|c|c|c|}
\hline$/ \mathrm{k}^{\mathrm{h}} \mathrm{a} /+/ \mathrm{il}+\mathrm{a}_{\mathrm{L} 2}$ & *HIATUS L2 2 IDENT & $\begin{array}{l}\text { IDENT I } \rightarrow \mathrm{O} \\
{[\text { ATR }]}\end{array}$ & $\begin{array}{r}\text { UNIFORM[-ATR] } \\
+ \text { +ATR] }\end{array}$ & HIATUS \\
\hline a. $\mathrm{k}^{\mathrm{h}}$ oila & (*)! & & & * \\
\hline b. $\mathrm{k}^{\mathrm{h}}$ ola & ! ! & & $*$ & * \\
\hline c. $\mathrm{k}^{\mathrm{h}}$ aila & *! & & $*$ & * \\
\hline d. $\mathrm{k}^{\mathrm{h}} \mathrm{ala}$ & 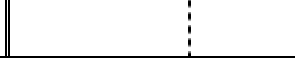 & * & & \\
\hline
\end{tabular}

The

optimal output candidate $/ \mathrm{k}^{\mathrm{h}} \mathrm{ala} /$ violates IDENT $\mathrm{I} \rightarrow \mathrm{O}[\mathrm{ATR}]$ as it does not preserve the features of the deleted segment faithfully. The higher ranked status of IDENT[low] prevents the selection of candidates (47) -a, b and c.

The hierarchy proposed till now is ranked as below:

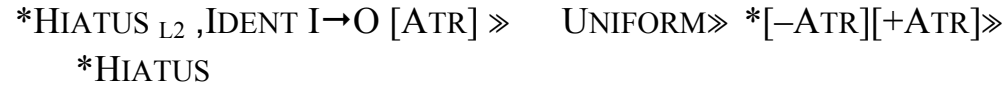

The examples like/roisu/, etc. which do not incur violation of *HIATUS also needs to be accounted for in this analysis. These instances of non-applicability 
of exceptional hiatus resolution are a result of non-indexation of these verbal morphemic extensions to any constraint demanding exceptional hiatus resolution. Hence this shows that the proposed analysis correctly predicts prevention of hiatus resolution if the concerned morpheme is not indexed. In those cases, hiatus resolution is entirely absent in the juncture where the morphemes come together.

No hiatus resolution when the morpheme is /-is/

Fi-

\begin{tabular}{|l||l|l|l|l|l|}
\hline$/ \mathrm{r} /$ /+/is/+/a/ & $\begin{array}{l}\text { HIATUS } \\
\text { L2 }\end{array}$ & $\begin{array}{l}\text { IDENT } \\
\text { I } \rightarrow \mathrm{O} \\
\text { [ATR }]\end{array}$ & UNIFORM & $\begin{array}{l}*[-\mathrm{ATR}] \\
{[+\mathrm{ATR}]}\end{array}$ & $*$ HIATUS \\
\hline a. ${ }^{\text {roisa }}$ & & & & & $*$ \\
\hline b. rosa & & & $* !$ & & $*$ \\
\hline c. roisa & & & & $* !$ & $*$ \\
\hline
\end{tabular}

nally

recall that in Assamese, there are instances of epenthesis in other parts of the lexicon. The hierarchy proposed till now successfully accounts for these instances as well.

*HIATUS and epenthesis

In

\begin{tabular}{|c|c|c|c|c|}
\hline misa+iya & $\begin{array}{c}* \text { HIATUS } \\
\text { :IDENT I } \rightarrow \text { O } \\
:[\mathrm{ATR}]\end{array}$ & UNIFOR & $\begin{array}{c}M\left[\begin{array}{l}* \text { ATR }] \\
{[+ \text { ATR }]}\end{array}\right. \\
\end{array}$ & $*$ HiATUS \\
\hline a. misaliya & & & $* !$ & \\
\hline b. misoliya & & & & \\
\hline c. misoya & & $* !$ & & \\
\hline d. misoiya & & & & $* !$ \\
\hline
\end{tabular}

these examples, hiatus is undone by epenthesising /1/ and /r/ respectively and even though *HiATUS is low-ranked it plays an active role in choosing the candidate without any hiatal gap.

There are instances of epenthetic / $/ /$ and $/ \mathrm{r} /$ in Assamese, probably because coronals are unmarked epenthetic segments. Although I cannot add anything thought-provoking with regard to the choice between $/ 1 /$ and $/ \mathrm{r} /$, the featural value of epenthetic segments has been given phonological interpretation in earlier work, for example in Yawelmani Yokuts harmony (Kuroda 1967 and Archangeli 1985). More work in the featural content of these epenthetic elements 
in the examples in (33) may throw light on this area in future. But it may be mentioned that since Prince \& Smolensky (1991), the idea that epenthetic elements are not physically added as full-fledged segments has gained currency. Phonological epenthesis is only a place-holder for prosodic structure and phonological constraints determine their featural specifications. For the time being, ignoring the featural content of the epenthetic elements brings us to the hierarchy discussed till now as an instance of how epenthetic behaviour can be fully accounted by the constraint hierarchy posited.

The tableau above shows that even though *HIATUS is low-ranked, its presence in the hierarchy is responsible for ensuring that hiatus can still be resolved by epenthesis. The activity of *HIATUS constraint here is again reminiscent of emergence of the unmarked. A point of significance here is also that whenever there is scope for possible interaction between the determinants of exceptional behaviour, there is none. In the tableau in (50), /misa/ 'lie' +/ -iya/ SuFfIX the output /misoliya/ violates IDENT LOW, but exhibits the unmarked pattern of syllabification, i.e. by epenthesis. At the same time, in the verbal pattern, emergent unmarkedness shows up when $/ \mathrm{kha} /$ 'eat' $+/-\mathrm{il} /+/-\mathrm{a} /$ leads to $/ \mathrm{khala} /$, an output where deletion is preferred over epenthesis, but IDENT LOW remains unviolated. In all these instances of morphology-phonology interface at the stem-suffix boundaries, there is no overlap which would result in highly marked patterns of syllabification and alternation, leading to the reinforcement of one of the primary assumptions of OT, that markedness is relative.

\subsection{Conclusion}

In the final reckoning, exceptional behaviour is dependent on the morpheme's selection of the relatively unmarked. This leads us to advocate for a proposal of the emergence of the relatively unmarked in the light of the exceptional processes discussed in this paper. Therefore this paper posits the view that there can be no default unmarkedness, but only emergent unmarkedness depending on the relevant morphological contexts. This view therefore repudiates the one put forward by Alderete $(1999,2001 \mathrm{a})$ where the outputs of morphophonological processes are supposed to be constrained by the grammar of the individual language (see also Inkelas and Zoll 2003). As we have seen from the Assamese examples, the attribute of 'grammar dependence' does not hold any water insofar as the exceptional morpho-phonological interactions are concerned.

A theoretical approach which would founder with respect to the Assamese patterns of morpho-phonological interaction is that of cophonology, more specifically in the manner argued by Anttila (2002), one of the main proponents of the cophonology approach. Cophonology in general requires exceptionalities in the lexicon and morphology to be analysed with the aid of lexically specified 
rankings of constraints which are already present in the grammar. In this approach propagated by Anttila (2002) only pairs of constraints whose ranking is unspecified in the grammar can have lexically specified rankings. When a lexical item is unspecified for the respective ranking, it would show variation. In the case of the exceptions of the emergent variety, no such pairing is possible. In these cases, a low ranked constraint supercedes all other Markedness and Faithfulness Constraints to assume precedence over them. Anttila (2002) also presents this model to establish a connection between exceptionality and variation, so that whenever the constraints are unranked the resultant output has the potential to vary either on the Markedness or on the Faithfulness count. This kind of variation is not attested in Assamese and therefore this attribute of Cophonology cannot be applicable to all instances of exceptionality in the grammar of languages. Further, as argued in Pater (2006), Anttila (2002) cannot elegantly capture local effects of constraints which are active in exceptional triggering and blocking.

To summarise the instances of exceptionality discussed in this paper, we can recall that exceptionality was divided between exceptional patterns in the nominal morphology as well as the verbal morphology. In the first case, a morpheme is expressed on the otherwise non-participating vowel /a/. In traditional terms, this function of the morpheme can be seen as an overapplication of harmony, which otherwise applies only to $[+\mathrm{High}-\mathrm{ATR}]-/ \mathrm{v} /$ or $[-\mathrm{High}-\mathrm{ATR}]-/ \varepsilon /$ and /o/ vowels but never to a [+Low - ATR] vowel - /a/. The application of harmony in this context violates the constraint IDENT [Low], which is otherwise highly ranked in the normal phonology of Assamese. Furthermore, by initiating progressive front harmony from root outwards, the morphemes /-iya/ and /-uwa/ faithfully observe universally attested principles of front harmony. Even though this exceptional pattern apparently violates the universal metaconstraint on higher ranked root faithfulness than affix faithfulness, it is argued in this paper that the resultant exceptional processes are not determined by language-specific determinants of markedness, but rather supports a more holistic approach to the markedness of exceptional patterns in languages. In exceptional patterns relating to hiatus resolution, it is shown that morphemes differ in their choice of syllabification because unmarkedness is again not a static choice, and its dynamism may be relative, governed by various factors which determine unmarkedness.

\section{Acknowledgements}

I have benefited from the observations of an anonymous reviewer in presenting the subject matter clearly. In various other occasions, the critical observations of 
Morpheme specific exceptional processes and emergent unmarkedness 29

Janet Grijzenhout, Joe Pater and Wim Zonneveld have also led to substantial improvements. Remaining errors of understanding and analysis are mine. 


\section{References}

Alderete, John

2001 Dominance effects as Transderivational Anti- Faithfulness. Phonology 18: 201-253.

Anttila, Arto

2002 Morphologically conditioned phonological alternations. Natural Lan-

Archangeli Diana guage and Linguistic Theory 20(1):1-42.

1985 Yokuts harmony: evidence for coplanar representations in nonlinear phonology. Linguistic Inquiry 16: 335-72.

Bakovic, Eric

2000 Harmony, Dominance and Control. Doctoral dissertation, University of California, San Diego.

Fukuzawa, Haruka

1999 Theoretical implications of OCP Effects on features in Optimality Theory. Doctoral dissertation, University of Maryland, College Park.

Benua, Laura

$2000 \quad$ Phonological relations between words. New York: Garland Press.

Gelbart, Ben

2005 The Role of Foreignness in Phonology and Speech Perception. Doctoral dissertation, University of Massachusetts, Amherst.

Goswami, Golok Chandra

1982 Structures of Assamese. Gauhati University: Department of Publication.

Horwood, Graham

1999 Anti-faithfulness and subtractive morphology. Ms, Rutgers University, New Brunswick, NJ. ROA-466.

Inkelas, Sharon and Cheryl Zoll .

2003 Is grammar dependence real? Ms, UC Berkeley and MIT. ROA-587.

Itô, Junko and Armin Mester.

1999 The Phonological lexicon. In Handbook of Japanese Linguistics, N. Tsujimura (ed.), 62-100.Oxford: Blackwell.

Itô, Junko and Armin Mester

2001 Covert generalizations in Optimality Theory: the role of stratal faithfulness constraints. Studies in Phonetics, Phonology, and Morphology 7: 273-299.

Kiparsky, Paul

1973 Abstractness, opacity, and global rules. In Three Dimensions of Linguistic Theory, O. Fujimura (ed.), 57-86.Taikusha: Tokyo.

Kiparsky, Paul

1993 Blocking in non-derived environments. In Studies in Lexical Phonology,

S. Hargus and E. Kaisse (eds.), San Diego: Academic Press.

Karvonen Daniel and Adam Sherman 
Morpheme specific exceptional processes and emergent unmarkedness 31

1997 Sympathy, opacity and u-umalaut in Icelandic. Phonology at Santa Cruz 5 37:38.

Krämer, Martin

2003 Vowel harmony and correspondence theory. Berlin: Mouton de Gruyter.

Kraska-Szlenk, Iwona

1997 Exceptions in phonological theory. Proceedings of the 16th International

Kuroda. S. Y. Congress of Linguists. Pergamon, Oxford: Paper No. 0173.

1967 Yamelmini Phonology. Cambridge, Mass: MIT Press.

Lubowicz, Anna

2002 Derived environment effects in Optimality Theory. Lingua 112: 243-280.

Mahanta, Shakuntala

2008 Directionality and Locality in vowel harmony: with special reference to vowel harmony in Assamese. LOT: Utrecht.

McCarthy, John and Alan Prince

1993 Generalized alignment. In Yearbook of Morphology, G. E. Booij and J. van Marle (eds.), 79 153. Dordrecht: Kluwer.

McCarthy, John and Alan Prince

1995 Faithfulness and reduplicative identity. UMOP 18:249-384.

McCarthy, John and Alan Prince

1999 Faithfulness and identity in prosodic morphology. In The Prosody-Morphology Interface, Rene Kager, Harry van der Hulst and Wim Zonneveld (eds.), 218-309. Cambridge: Cambridge University Press.

Pater, Joe

2000 Nonuniformity in English stress: the role of ranked and lexically specific constraints. Phonology 17:237-274.

Pater, Joe

2006 The locus of exceptionality: Morpheme-specific phonology as constraint indexation. In University of Massachusetts Occasional Papers in Linguistics 32: Papers in Optimality Theory III, Leah Bateman, Michael O'Keefe, Ehren Reilly, and Adam Werle (eds.), Amherst: GLSA.

Prince, Alan and Paul Smolensky

2004 Optimality Theory: Constraint interaction in Generative Grammar. Oxford: Blackwell.

Revithiadou, Anthi

1998 Headmost accent wins: Head dominance and ideal prosodic form in lexical accent systems. The Hague: Holland Academic Graphics.

Tunga, S.S.

1995 Bengali and other related dialects of South Assam. New Delhi: Mittal Publications. 
1 The status of these and other lexical items which are deemed to be roots in this paper are not subject to any dispute. They also do not alternate in the presence of non-ATR suffixal vowels. For instance /upor/ 'top' +/ot/ $\rightarrow$ /uporst/ 'on top' and /khoros/ + /or/ $\rightarrow /$ khorosor/ 'of expenses' /tzl/ + /al/ $\rightarrow$ 'having a lot of oil'

2 The ranking of *[-ATR][+ATR] below IDENT [High] and *[-ATR, +High, - Back $]$ is required because of blocking by $/ \mathrm{a} /$.

3 This does not imply that I am arguing for a structure preserving (Kiparsky 1973) approach to Assamese harmony. The very fact that the outputs of harmony, i.e. [e] and [o] have an allophonic status shows that such an approach will not reflect the actual harmonic process of Assamese.

4 These two suffixes trigger another type of alternation when they are preceded by words with a mid-low vowel followed by a low vowel. These are illustrated in (18) and discussed immediately thereafter.

5 /-iya/ and /-uwa/ behave in a largely equivalent manner insofar as their involvement in exceptional patterns is concerened. Therefore any reference to only one of them implies reference to the other one as well.

6 In contrast, $/ \mathrm{a} /$ in a root/stem position never alters the [ \pm Back] quality of the prefixal vowel. /a/ following a prefixal position always shifts to $/ \mathrm{o} /$.

7 Nothing much can be said about the epenthetic $/ 1 /$ here. There are a few instances of epenthetic $/ 1 /$ and $/ \mathrm{r} /$ in Assamese.

8 The ranking is not reflected here, but it will be shown in all other instances where /a/ alters to /e/ when the mid vowel precedes it.

9 Front harmony is not instantiated anywhere in Assamese.

10 See also other work which argue against the metaconstraint FAITH ROOT $>$ FAITH AFFIX, especially, Karvonen and Sherman (1997), Krämer (2003), Revithiadou (1998).

11 I refer to the surface inventory of Assamese which, undoubtedly, also consists of [e] and [o] albeit with restrictions. Although there may be some circumspection whether segments like [e] and [o] should be considered to be a part of the language's vowel inventory, this approach was necessitated because of the existence of $[\mathrm{e}]$ and $[\mathrm{o}]$ in some non-alternating contexts as well (see Mahanta 2008). Although these occurrences can very well be called exceptional, the significance of gradient phonological behaviour displayed by [e] and [o] needs to be highlighted. These reasons have led to the tacit assumption in this paper that [e] and [o] are perhaps in an intermediate stage between allophony and non-allophony.

12 Verbal roots which are considered for analysis are the barest forms of the verb without any additional person, number, tense, aspect or modal markers. As such, these bare forms without any markers are used in the imperative (in the sense of a command or a direction) and can be used only non-honorifically.

13 In his typological study, Casali (1997) notes that in a root and suffix boundary, if the suffix is VC, a ranking of MAX Ms (a constraint preserving all input segments) over MAX LEX (a faithfulness constraint protecting lexical words) would produce a deletion pattern, such as the one instantiated in Assamese. A discussion of various typological issues, as the ones raised by Casali, is outside the scope of this paper. 
${ }^{14}$ A referee has pointed out the need to defend a hiatus avoidance analysis instead of an allomorphy analysis. I contend that even an allomorphy analysis is bound to address and analyse the same questions posited here. In other words, the phonological conditioning of the allomorphs / $/ \mathrm{l} / /-\mathrm{b} / /-\mathrm{m} /$ vis-a-vis / $-\mathrm{i} \mathrm{l} / /-\mathrm{ib} / /-\mathrm{im} /$ will also stumble into the problem of hiatus avoidance. My approach in this paper argues for lexical indexation of the concerned morphemes instead of storing them as different allomorphs, as lexical indexation comes with built-in mechanisms for factors such as locality, which the phenomena under discussion complies with, whereas other analyses lack those means of analysing locality.

15 The underlying forms that are hypothesised for the suffixes show that hiatusavoidance results in epenthesis. The strategy involved in these forms show two types of epentheis - / $/ /$ epentheis in the presence of two vowels and $/ \mathrm{o} /$ epenthesis in the presence of two consonants. $/ \mathrm{J} /$ harmonises to $/ \mathrm{o} /$ if there is a following $/ \mathrm{i} /$. 